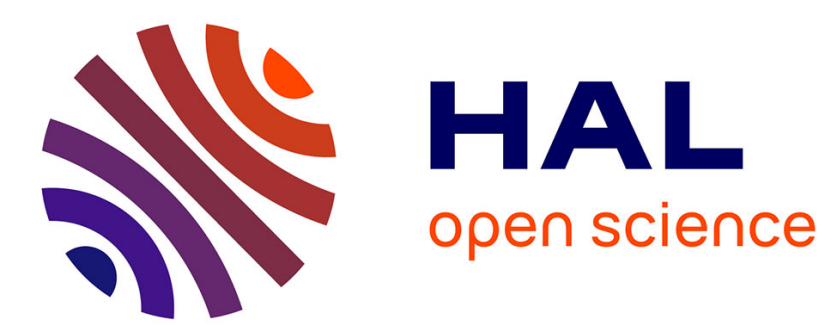

\title{
PYRAMID SPECTRAL ANALYSIS OF NARROW-BAND SIGNAL
}

\author{
Y. Wang, W. Lu, Di Hu, L. Zhao, J. Xu
}

\section{To cite this version:}

Y. Wang, W. Lu, Di Hu, L. Zhao, J. Xu. PYRAMID SPECTRAL ANALYSIS OF NARROW-BAND SIGNAL. Journal de Physique Colloques, 1990, 51 (C2), pp.C2-737-C2-740. 10.1051/jphyscol:19902171 . jpa-00230475

\section{HAL Id: jpa-00230475 https://hal.science/jpa-00230475}

Submitted on 1 Jan 1990

HAL is a multi-disciplinary open access archive for the deposit and dissemination of scientific research documents, whether they are published or not. The documents may come from teaching and research institutions in France or abroad, or from public or private research centers.
L'archive ouverte pluridisciplinaire HAL, est destinée au dépôt et à la diffusion de documents scientifiques de niveau recherche, publiés ou non, émanant des établissements d'enseignement et de recherche français ou étrangers, des laboratoires publics ou privés. 


\title{
PYRAMID SPECTRAL ANALYSIS OF NARROW-BAND SIGNAL
}

\author{
Y.M. WANG, W.X. LU, D.K. HU, L.Y. ZHAO and J. XU \\ Institute of Biomedical Engineering, zhejiang University Hangzhou, \\ 310027, China
}

\begin{abstract}
In this paper, a novel scheme using pyramid is proposed which computes the narrow-band spectrum with good resolution while reauiring only modest computation and storage.
\end{abstract}

1. Introduction

The calculation of the spectrum of a narrow-band signal which is embedded in a broad-band sequence usually recuires substatial computation and storage if executed by performing an FFT or DFT's directly on the broad-band sequence.

In orevious works, The zoom transform and a modified zoom were proposed to compute the marrow-band spectrum with less storage than the FFT approach. Another proposed scheme [1] first modulates the signal with complex exponentials, then decimates, and finally analysis the decimated signal. Liu and Mintzer [1] proposed a good scheme first decimates the signab, then uses multirate bandpass filtering, The signab band of interest can be shifted to low frealencies, the sampling rate can be reduced to twice the band-width of the desired sigmal, and a low-order fFT analysis can be performed, giving the desired high-resolwtion, narrow-band spectral data. It combines the advantases of both a small computation rate and a small storage reculrement.

In this paper, we proposed a novel soheme for pyramid spectral analysis of a narrow-band signal. In a pyramid spectral analysis, an original signal is first bandpass filtered to isolate the desired band of interest, and the resulting signal is sucessively pyramid low-pass filtered and decimated to form a compact representation of the signal. To obtain the desired high-resolution, narrow-band spectrum, a low-band FFT anabysis can be performed on pyramid data.

2. Gaussian Pyramid

Burt and Adelson [2] have proposed a Gaussian filter to form the pyramid. The Gaussian pyramid is a sequence of signal in which each is a Low-pass filtered copy of its predecessor. Let sequence $x_{0}$ be the original signal; this becomes the bottom, or zero level of the pyramid. Each node of the next pyramid level, sequence $x_{1}$, is obtain as a weighted average of $x$. . Nodes within a 5. whdow. Each node of $x_{2}$ is then obtained from $x_{1}$ by applying the same pattern of wejghts. Note that the sample distance in each level is double that in the previous level. As a result, each signal in the sequence is represented by a sequence which is half as lapge as its predecessor. If we imagine these secilince stacked one above another, the result is the tapernig pyramid data structure.

The process which generates each seqwence from its predecessor will be called a REDUCE operation since both resolution and sample density are decreased. Let $x_{0} b e$ the original signal and let $x_{m}$ be the top level of the pyramid. Then for $0 \leqslant L \leqslant M$, we say

$\begin{aligned} x_{l} & =R E \\ \text { which } & \text { means }\end{aligned}$

$$
x_{l}=\text { REDUCE }\left[x_{d-1}\right]
$$




$$
x_{l}(i)=\sum_{m=-2}^{l} w(m) x_{l-1}(2 i+m)
$$

The weighting function $w$ is called the generating kernel. This is chosen subject to three constraints. It is
(i)
( $(i \mathrm{i})$
Normalized:
Symetrio :$$
\Sigma w(m)=1
$$$$
w(m)=w(-m)
$$

( $i j i)$ Equal contribution: $w(0)+w(-2)+w(2)=w(-1)+w(-1)$

Combining constraints we have

$w(0)=$ free varible

$w(-1)=w(1)=0.25$

$w(-2)=w(2)=0.25-0.5 * w(0) ;$

Iterated pyramid generation is equivalent to convolving the signal with a set of "equivalent weighting function" hl:

$$
\text { or } x_{l}=h_{l}(i)=\sum_{m=-M_{l}}^{M} h_{l}(m) x_{0}\left(i * 2^{l}+m\right)
$$

The size $M$ of the equivalent weighting function doubles from one level to the next, as does the distance between samoles. The effect of convolving a signal with one of the equivalent weighting function hl is to blur, or Low-pass filter, the signal. The pyramid algorithm reduces the filter band limit by an octave from level to level, and reduces the sample interval by the same factor. This is a very fast algorithm, requiring fewer computational steps to compute a set of filtered signals than are required by FFT to compute a single filtered signal.

3. Narrow-Band: High-Resolution Spectral Analysis Using Pyramid method

One of the most fundamental signal processing operations is spectral analysis: that is evaluation of the $z$-transform of a sequence over a band of frequences on the unit circle. Formulally, if we define an N-point sequence, $x_{0}(n), n=0, \ldots, N-1$, with $z$-transform

$$
x_{0}(t)=\sum_{n=0}^{N-1} x(n) z^{-n}
$$

then the spectrum of $x_{0}(n)$ at frequence w is

$$
x_{0}\left(e^{j \omega}\right)=x(z) \sum_{z=e^{j \omega}=\sum_{n=0}^{N-1} x_{0}(n) * e^{-j \omega n}}
$$

Although a variety of techniques have been proposed for evaluating $x_{0}\left(e^{j u}\right.$ of Eq. (5), perhaps the most commonly used one is the class of FFT algorithms. These algorithms evaluate, in an efficient manner, the 2 -transforms of a finite sequence at a set of equal spaced frequencies

$$
w=k * \frac{2 \pi}{N} \quad, k=0,1, \ldots, N-1
$$

giving

$$
x_{0}\left(e^{j \omega_{k}}\right)=x_{0}(k)=\sum_{n=0}^{N-1} x_{0}(n) * e^{-j(2 \pi / N) n k}
$$

From the set of FFT coefficients $x_{0}(k), k=0,1, \ldots, N-1$, the original sequence can be calculated $v i a$ an inverse FFT relation of the form

$$
x_{0}(n)=\frac{1}{N} \sum_{n=0}^{N-1} x_{0}(k) * e^{j(2 \pi / N) n k}
$$


The set of FFT and inverse FFT relations, of Eas.(7) and (8), provide a powerful framework for wide-band digital spectral analysis of signals, and have been wsed in this manner in a wide variety of applications.

one major disadvantage of the FFT algorithm is that is automatically provides spectral information over a uniformly spaced set of frequencies covering the entire band of the signal of interest. For some applications only the spectral and for "such cases if is highly inefficient to make all the calculations of $E q .(7)$ and then to use a small subset of them. By using the narrow-band filtering and pyramid reduce, the signal band of interest can be shifted to low frequencies, and a low-order FFT analysis can be performed, giving the desired high-resolution, narrow band spectral data.

Fig. 1 illustrates the principle used to derive a pyramid structure for high-resolution, narrow-band spectral analysis. In Fig.1.(a) we show the pyramid structure for bandpass filtering for an integer-band signal. The decimation rate of the mult ilevel pyramid reduce operation's is M/, defined as

$$
M_{l}=\frac{\pi}{\omega_{s_{x}}-\omega_{s_{l}}}
$$

where $w_{s p}$ and $w_{s_{u}}$ are the lower and upper frequencies of interest in the bandpass signal. The signal is first bandpassfiltered to isolate the desired band of interest, and the resulting is decimated by a factor of M. since we assumed integer-bands, we have

$$
\begin{aligned}
& w_{s_{l}}=\frac{l \pi}{M l} \\
& w_{s_{l}}=\frac{l+1, \pi}{M_{l}}
\end{aligned}
$$

$(10 b)$

for some value of $L, t \leqslant L \leqslant M-1$. The resulting signal, $x$ f $m$ ), has a lowpass spectrum as shown in Fig.1.(b). For the lowpass signal (assuming negligible aliasing), the freauency whorrespongs to the frequency $w$ in $x_{0}\left(e^{j} \boldsymbol{w}_{\text {) }}\right.$ such that

$$
w^{\prime}=\frac{\left(w-w_{y / g}\right)}{w_{s_{u}}-w_{s}}
$$

To obtain the desired high-resolution, narrow-band spectrum, the system of Fig.1.(c) is used, in which an N-point FFT is performed on $x$ (m), yielding spectral values for frequencies

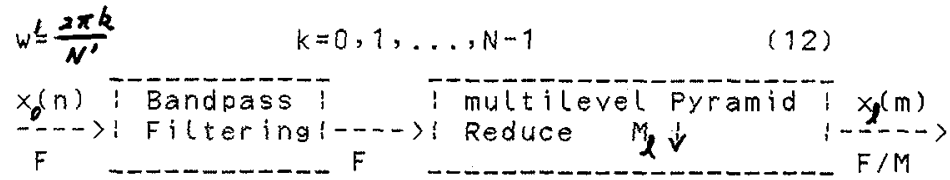

(a)

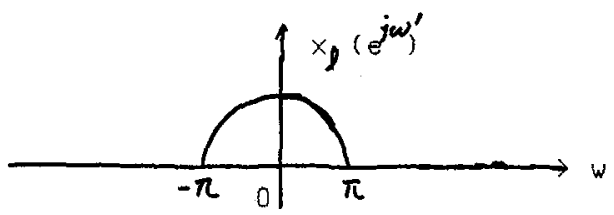

(b) 


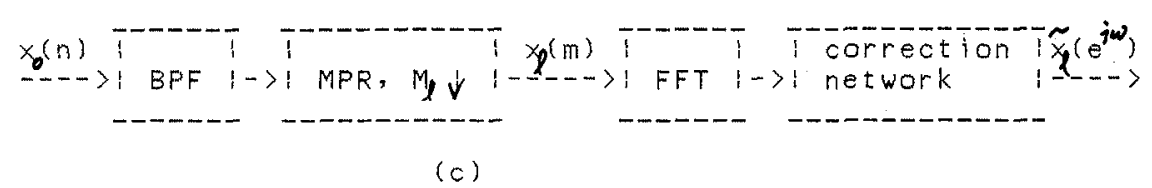

Fig. 1 Multilevel pyramid structure for performing

high-resolution narrow-band spectral analysis.

and these values are translated back to the wrange using Eq. (11). The value of $N^{\prime}$ is, approximately,

$$
N^{\prime}=\frac{N}{M l}
$$

since the pyramid decimated signal has only $N / M_{l}$ samples. Acorrection network is shown which can correct for the imperfect passhand response of the passband filter.

The improvement in efficiency derives from the use of a pyramid reduction operation and a considerably smaller value of $N$ than $N$, whenever Mp is large, thereby reducing the FFT computation, which is proportional to NogN. However, there is extra computation due to the bandpass filter. For most cases of interest bands where $M \geqslant 10$, there is a real reduction in computation wsing the pyramid structure of Fig.1.(c) over the direct FFT computation.

\section{Discuccion}

Pyramids, in generab, are data structures that provide successively condensed representations of the information in the input signal. Many basic signaloperations may be performed efficiently within pyramid structures. Pyramid reduction operation can generates of low-pass filtered signals at a fraction of the cost of FFT. Local signal properties can be estimated with equal efficlency within Gaussian-like windows of many sizes. Here the pyramid will be viewed primarily as a computational tool for spectral analysis.

\section{References}

1. B.Liu and F.Mintzer, "Calculation of Narrow-Band Spectra by Direct Decimation". IEEE Trans. Acoust. Speech Signal Process." Vol. ASSP-26, No.6, P529-534, DeC. 1978 .

2. P.J.Burt and E.H.Adelson, "The Laplacian. Pyramid as a compact Image Code", IEEE Trans. Commun., Vol. COM-31, Vol.4, p532-540, Apr. 1983. 